\title{
Sex Differences in the Outcomes of Elderly Patients With Heart Failure With Preserved Ejection Fraction
}

\author{
Jiaxing Sun \\ Second Xiangya Hospital \\ Shi Tai \\ Second Xiangya Hospital \\ Guo Yanan \\ Second Xiangya Hospital \\ Liang Tang \\ Second Xiangya Hospital \\ Hui Yang \\ Second Xiangya Hospital \\ Xuping Li \\ Second Xiangya Hospital \\ Zhenhua Xing \\ Second Xiangya Hospital \\ Liyao Fu \\ Second Xiangya Hospital
}

Shenghua Zhou ( $\nabla$ zhoushenghua@csu.edu.cn )

Second Xiangya hospital https://orcid.org/0000-0002-2830-6787

Research article

Keywords: elderly patient, HFpEF, sex differences, outcome

Posted Date: February 23rd, 2021

DOI: https://doi.org/10.21203/rs.3.rs-236764/v1

License: @ (i) This work is licensed under a Creative Commons Attribution 4.0 International License. Read Full License 


\section{Abstract}

Background: It has been shown the impacts of sex on patients' outcomes with preserved ejection fraction (HFpEF), but little is known about the impacts of sex on elderly patients with HFpEF.

Methods: A secondary analysis was conducted to evaluate the impacts of sex on outcomes of patients who were $\geq 70$ years of age with HFpEF from the Treatment of Preserved Cardiac Function Heart Failure with an Aldosterone Antagonist Trial (TOPCAT). The primary outcome was composed of cardiovascular (CV) mortality, HF hospitalization. Secondary outcomes included all-cause mortality and all-cause hospitalization. Cox regression models were used to determine sex differences in outcomes.

Results: A total of 1619 patients were included: 898 (55.5\%) women and 721 (44.5\%) men. Their age ranged from 70 to 94 years, similar between women and men. Women had fewer comorbidities than men. The rate of primary outcome was lower in women than in men (18.9\% vs. $28.1 \%, \mathrm{p}=0.002)$, including CV mortality (10.6\% vs. $15.4 \%, p=0.039)$ and HF hospitalization (13.5\% vs. $19.0 \%$, $p=0.033)$. After adjustment for baseline characteristic, the Cox regression analysis showed that woman was a protective factor for CV mortality (hazard ratio [HR] 0.53, 95\% confidence interval [Cl] 0.40-0.73), HF hospitalization (HR $0.71,95 \% \mathrm{Cl} 0.55-0.93)$ and all-cause mortality (HR 0.59, 95\% $\mathrm{Cl} 0.47-0.75)$. Although a significant reduction in all-cause mortality associated with spironolactone in women was observed even after adjustment (HR: $0.68 ; 95 \% \mathrm{Cl}: 0.48-0.96 ; p=0.028)$, there is not a significant multivariate sex-treatment interaction ( $\mathrm{p}$ interaction $=0.190)$.

Conclusion: Among elderly patients with HFpEF, women had fewer comorbidities and better outcomes.

Clinical trial registration: NCT00094302 (TOPCAT). Registered 15 October 2004, https://www.clinicaltrials.gov/ct2/show/NCT00094302

\section{Background}

The risk of heart failure with preserved ejection fraction (HFpEF) increases with advancing age. Patients with HFpEF are older than HF patients with reduced ejection fraction (HFrEF); With aging, the incidence and prevalence of HFpEF increase more rapidly [1]. These elderly patients are under-represented in randomized clinical trials, and the clinical features, event rates, response for treatments could be different from young patients.

Indeed, sex differences existed in almost every facet of HF (both HFrEF and HFpEF), including baseline characteristics, risk factors, pathophysiology, response to drugs, and different outcomes[2,3]. Community-based studies indicated that women are substantially different from men concerning clinical features and event rates[4, 5]. The Irbesartan in heart failure with Preserved Ejection Fraction (I-PRESERVE) trial, including about 2500 women patients, showed that women had a lower risk of mortality or hospitalization for both cardiovascular and non-cardiovascular events, suggesting women had better overall prognosis[6]. The large randomized placebo-controlled trial TOPCAT showed no significant interactions between spironolactone arm and sex concerning the primary outcome in a pre-specified subgroup analysis of the full TOPCAT cohort [7]. In contrast, the secondary analysis restricted to the Americas observed a significant reduction in all-cause mortality associated with spironolactone in women but not in men[8]. These findings suggested a positive effect of spironolactone in women with HFpEF but not in men.

However, information regarding the impacts of sex on outcomes and response to spironolactone in elderly patients with HFpEF is limited. In the present study, we did a post-hoc, exploratory subgroup analysis in elderly patients from the TOPCAT study to discuss differences in baseline characteristics, outcomes, and response to spironolactone between elderly women and men with HFpEF.

\section{Methods}

\section{Study design and patients}

In the present study, we used TOPCAT clinical data obtained from the National Heart, Lung, and Blood Institute's Biological Specimen and Data Repository Information Coordinating Center (BioLINCC, Calverton, Maryland). Patients were eligible if they were diagnosed with symptomatic HF and LVEF $\geq 45 \%$ combined with either a hospitalization for HF within 12 months before inclusion or an elevated natriuretic peptide level (brain natriuretic peptide [BNP] $\geq 100$ $\mathrm{pg} / \mathrm{mL}$ or N-terminal pro-BNP [NT-proBNP] $\geq 360 \mathrm{pg} / \mathrm{mL}$ ) within 60 days before inclusion. Patients had to be aged $\geq 50$ years, have controlled systolic blood pressure $<140 \mathrm{mmHg}$ (or $\leq 160 \mathrm{mmHg}$ if the patient was taking three or more medications to control blood pressure), and a serum

potassium level $<5.0 \mathrm{mmol} / \mathrm{L}$. The main exclusion criteria were life expectancy $<3$ years, estimated glomerular filtration rate (eGFR) $<30 \mathrm{ml} / \mathrm{min} / 1.73 \mathrm{~m}{ }^{2}$ body surface area or serum creatinine $\geq 2.5 \mathrm{mg} / \mathrm{dL}$. The detailed inclusion and exclusion criteria were described in the main study publication [7, 9]. Patients were randomized in a double-blind fashion to receive either spironolactone or placebo therapy. For this study, 1619 elderly patients (age $\geq 70$ years)[10, 11] were selected from the TOPCAT trial, and a secondary analysis was conducted.

\section{Definitions and endpoints}

The mean follow-up time was 3.3 years. The primary outcomes were composed of cardiovascular (CV) mortality, HF hospitalization. Secondary outcomes for the present analysis included all-cause mortality consisted of CV and non-CV mortality, and all-cause hospitalization.

\section{Statistical analysis}

Data were stratified according to sex and treatment arm. Descriptive statistics were obtained for all study variables. Baseline clinical characteristics of patients were expressed as mean (SD) or median (interquartile range [IQR]) values for continuous variables, frequencies, and percentages for categorical 
variables. The presence of sex differences in outcomes was compared between men and women within the placebo arm, spironolactone arm, and all patients. All categorical variables were compared using the Fisher's exact test or $\chi^{2}$ test, and continuous variables were compared using the t-test or the Mann-Whitney $\mathrm{U}$ test, as appropriate. Time-to-event curves were obtained using the Kaplan-Meier method. Univariate and multivariate Cox proportional hazards model was used to explore the associations between sex and the outcomes. Effects of intervention versus placebo on the outcomes were analyzed by sex. Adjustment variables included race, NYHA class, myocardial infarction (MI), percutaneous coronary intervention (PCI), coronary artery bypass grafting (CABG), atrial fibrillation (AF), hypertension, dyslipidemia, chronic obstructive pulmonary disease (COPD), systolic blood pressure (SBP), diastolic blood pressure (DBP), heart rate, body mass index (BMI), baseline estimated glomerular filtration rate (eGFR) and baseline potassium level. Statistical analyses were performed using Stata/S.E. version 15.1 software (Stata Corp., College Station, Texas). Sex-treatment interaction was analyzed using Empower Stats. A p-value <0.05 was considered significant throughout.

\section{Results}

\section{Characteristics of the patients according to sex}

The overall cohort $(n=1619)$ stratified by sex were described in Table 1 . Of the 1619 elderly patients, 898(55.5\%) were women, and $721(44.5 \%)$ were men. Their age ranged from 70 to 94 years, and the mean age was similar between women and men. Women from the Americas (including the United States, Canada, Brazil, Argentina) or Russia/Georgia were 533(59.4\%), 365(40.6\%), respectively.

The baseline characteristics of each group were listed in Table 1. Women had fewer comorbidities: AF (41.4\% vs. $47.4 \%$; $p=0.016)$, MI (18.7\% vs. $30.9 \%$; $p<0.001)$, CABG (7.6\% vs 22.3\%; $p<0.001)$, PCl (12.5\% vs $18.9 \%$; $p<0.001)$, dyslipidemia $(57.3 \%$ vs. $66.2 \% ; p=0.001)$, COPD (9.24\% vs. $47.4 \% ; p=0.001)$ ) .Moreover, women had a higher prevalence of hypertension ( $93.0 \%$ vs. $89.2 \%$; $p=0.007)$ than men. The prevalence of NYHA functional classes III-IV (38.5\% vs. $31.5 \%, p=0.003)$ and BMI $(30.9 \pm 6.2$ vs. $30.1 \pm 5.8, p=0.011)$ were higher in women than in men, whereas serum potassium $(4.2 \pm 0.43$ vs. $4.3 \pm 0.48, p=0.010)$, blood urea nitrogen( $16.2 \pm 14.2$ vs. $20.1 \pm 14.3, p=0.001)$, hemoglobin $(12.6 \pm 1.8$ vs. $13.3 \pm 2.4, p=0.001)$, and creatinine levels $(1.0 \pm 0.3$ vs. $1.3 \pm 0.31$, $p<0.001$ ) were lower in women than in men. Moreover, we observed the elderly women with HFpEF had higher LVEF, a higher rate of NYHA functional classes III-IV, and lower Kansas City Cardiomyopathy Questionnaire (KCCQ) scores than men in the present study.

Regarding the use of medications, there were no significant differences between men and women in the use of angiotensin-converting enzyme (ACE) inhibitors, angiotensin receptor blockers (ARB), beta-blockers, calcium channel blockers (CCB), or diuretics. Men were significantly more likely to take statin, warfarin, any hypoglycemic, other anti-hypertensive, and CV medications. Moreover, no matter in the placebo arm or the spironolactone arm, differences between women and men are the same as the whole cohort.

\section{Differences in outcomes between women and men}

Rates of primary and secondary outcomes stratified by sex for the placebo arm and spironolactone arm were summarized in Table 2. In all patients, the rates of all outcomes were significantly lower in women than in men. In the placebo arm, women had lower rate of primary outcome $(18.9 \% \mathrm{vs} .28 .1 \%, \mathrm{p}=0.002)$, CV mortality $(10.6 \%$ vs. $15.4 \%, p=0.039)$, HF hospitalization $(13.5 \%$ vs. $19.0 \%, p=0.033)$, and all-cause mortality $(31.5 \%$ vs. $50.4 \%, p<0.001)$ than men. The rate of all-cause hospitalization was numerically lower in women than in men, but there were no statistically significant differences. In the spironolactone arm, rates of primary outcome $(17.9 \%$ vs. $26.8 \%, p=0.002)$, CV mortality $(7.3 \%$ vs. $14.2 \%, p=0.001)$, all-cause mortality $(13.0 \%$ vs. $25.7 \%, p<0.001)$, all-cause hospitalization $(45.5 \%$ vs $53.4 \%, p=0.026)$ in women were significantly lower than in men. HF hospitalization rates were numerically lower in women than men, but there was no statistically significant difference. Kaplan-Meier curves for primary and secondary outcomes stratified by sex summarized in Figure 1 and Figure 2. Sex-specific univariate analysis showed that women had lower rates of all outcomes in all patients and the placebo arm. In the spironolactone arm, there were no significant differences in HF hospitalization (hazard ratios [HR] 0.73, 95\% Cl: 0.51-1.04, p = 0.083) and all-cause hospitalization (HR 0.71, 95\% Cl: 0.50-1.01, $p=0.058$ ) between women and men. sex-specific multivariate HR in the placebo arm and spironolactone arms for all outcomes adjusted for region, NYHA class, MI, PCI, CABG, AF, hypertension, dyslipidemia, COPD, SBP, DBP, BR, BMI, baseline eGFR, and baseline potassium levels were summarized detailly in Supplemental Table 1 and Figure 3. In the whole cohort, women had a significantly lower risk of the primary outcome, CV mortality, HF hospitalization, and all-cause mortality after adjusting the covariates. Importantly, both in the placebo arm and the spironolactone arm, there was a reduced likelihood of the primary outcome, CV mortality, and all-cause mortality in women but not in men.

\section{Treatment effect between women and men}

Univariate HRs for all outcomes were summarized in Table 3. In women patients, the primary outcome occurred in 84 patients (10.4\%) taking placebo and 81 patients (10.0\%) taking spironolactone, with a corresponding HR of 0.95 (95\% Cl: 0.70 to 1.29). Rates of CV mortality, HF hospitalization, all-cause mortality, and all-cause hospitalization were also numerically lower in patients treated with spironolactone but did not reach statistical significance (p凶0.05 for all outcomes). The spironolactone treatment effect was similar in men patients.

Multivariate HRs and interaction terms between sex and treatment response for outcomes were summarized in Supplemental Figure 1 and Table 3. There was no significant reduction in primary outcome associated with spironolactone in women (HR 0.91, 95\% Cl: 0.67-1.25, p=0.580) and men (HR 0.88, 95\% Cl: 0.661.17, $\mathrm{p}=0.377)$. Rates of CV mortality, HF hospitalization, and all-cause hospitalization all had no significant difference between placebo and spironolactone arm both in women and men ( $p>0.05)$. Although there was a decreased rate of all-cause mortality $r$ in women treated with spironolactone (10.0\% vs. $7.3 \%$, HR $0.68,95 \% \mathrm{Cl}$ : 0.48-0.96) but not in men, the sex-treatment interaction was not significant ( $\mathrm{p}$ interaction=0.190).

\section{Discussion}


Patients older than 70 years of age from the TOPCAT study were included in the present study, and sex differences in baseline characteristics and sex-specific advantages in outcomes were found: (1) elderly women with HFpEF had fewer comorbidities and better health conditions than men; (2) Elderly women had a lower risk of CV mortality than men either receiving placebo or spironolactone; (3) There was no significant reduction in primary outcome associated with spironolactone in elderly women and men, but elderly women taking spironolactone had lower all-cause mortality than those taking placebo.

Most patients with HF are above 65 years of age, and in many contemporary studies, a significant proportion of patients are 70 years of age or older. A prospective study enrolled 1203 patients with HFpEF from 11 Asian regions grouped patients into very young ( $<55$ years), young (55-64 years), older (65-74 years), and elderly ( $\geq 75$ years) [12], which showed that patients from different age groups have different clinical characteristics and outcomes. However, elderly patients are under-represented in randomized clinical trials. Specifically, prior reports from HF trials that examined sex differences included age $\geq 60$ years old in the I-PRESERVE (Irbesartan in heart failure with Preserved ejection fraction $₫$ study[6], age $\geq 21$ years old in the DIG-PEF[13], and age $\geq 50$ years old in the TOPCAT-Americas study[14]. Moreover, there were prominent sex differences in baseline characteristics in patients with HFpEF, but few studies focused on the sex differences of elderly patients with HFpEF. Therefore, in the present study, we included patients from the TOPCAT trial restricted to the elderly. We observed that among the elderly patients, women with HFpEF were more likely to have higher BMI, chronic kidney disease, and hypertension than men but less likely to have coronary artery diseases, tobacco use, AF, and COPD. These findings were in agreement with data derived from the I-PRESERVE study and the TOPCAT study. Another meta-analysis[8] including 4458 women and 4010 men with HFpEF enrolled in CHARM-Preserved (Candesartan in Heart failure: Assessment of Reduction in Mortality and morbidity) (EF $\geq 45 \%$ ), I-Preserve, and TOPCAT-Americas indicated that women were older and more often have obesity and hypertensive but less likely to have coronary artery disease or atrial fibrillation. These findings suggested elderly women with HFpEF had fewer comorbidities than men.

Moreover, we observed elderly women with HFpEF had higher LVEF, a higher rate of NYHA functional classes III-IV, and lower KCCQ scores than men. The results indicated elderly women were prone to have better heart function but had more symptoms and worse quality of life. This phenomenon was not unexpected. An observational study suggested that other factors may explain low life quality in women with HFpEF instead of HF itself, and the reason was multifactorial[15].

Although women with HFpEF were more likely to comorbid with hypertension, there were no significant differences between men and women in using antihypertensive drugs, including ACEI, ARB, beta-blocker, CCB, or diuretics. According to previous studies[16-19], we speculated that these findings might be attributed to different pharmacokinetics and pharmacodynamics. Women taking ACEI, ARB, and beta-blocker had higher plasma drug concentration than men. Men were more likely to be taking statin, warfarin, or hypoglycemic medications than women; these differences may be explained by the fact that men were more likely to comorbid with $\mathrm{AF}$, diabetes, and dyslipidemia in the present study.

Remarkably, elderly women had lower CV mortality rates and HF hospitalization than men among the patients taking placebo in the present study. This finding was in contrast with Merrill's report[14], which showed that women and men present with similar clinical outcomes. Specifically, CV mortality and HF hospitalization rates were numerically lower in women than in men ( $2.15 \%$ vs. $2.68 \% ; 3.79 \%$ vs. $4.43 \%$, respectively), but there were no statistically significant differences. Because our cohort only included patients of $\geq 70$ years of age, the above difference might be caused by different age groups. The secondary analysis using data from the I-PRESERVE study indicated that women had significantly lower mortality rates and HF hospitalization than men[6].

Moreover, the meta-analysis[8] indicated the risk of the primary outcome was lower in women (HR $0.80,95 \%$ Cl: $0.73-0.88$ ), as was the risk of cardiovascular death (HR 0.70, 95\% Cl: 0.62-0.80), but there was no difference in the rate for the first hospitalization for heart failure (HR $0.92,95 \% \mathrm{Cl}$ : $0.82-1.02)$. Among the patients taking spironolactone, elderly women had a lower CV mortality rate than men but not HF hospitalization. After adjusting for baseline characteristics, elderly women, who either took a placebo or spironolactone, had a lower risk of CV mortality. However, there was no difference in HF hospitalization risk between elderly women and men from the placebo arm and spironolactone arm. These findings suggested that women were at a lower risk of the primary composite endpoint than men due to a substantially lower risk of cardiovascular death but not HF hospitalization.

Previous individual patient-data meta-analysis[20] has shown that mineralocorticoid receptor antagonists (MRAs) reduced morbidity and mortality in elderly patients with HF, a beneficial effect that was more marked in patients with HFrEF but homogenous across HFrEF and HFpEF. Specifically, in elderly patients with HFpEF from the TOPCAT-Americas trial, the primary outcome of cardiovascular death or HF hospitalization occurred in 116 patients (32.7\%) taking placebo and 111 patients (28.1\%) taking MRA, with a corresponding HR of 0.83 ( $95 \% \mathrm{Cl}: 0.63$ to 1.08 ), suggesting spironolactone therapy failed to be associated with reduced CV mortality and HF hospitalization in elderly patients. After stratified by sex in the present analysis, there was no significant reduction in CV mortality and HF hospitalization associated with spironolactone in elderly women and men. The result kept in line with a previous study that showed the interaction between spironolactone and sex was nonsignificant for the CV mortality and HF hospitalization in TOPCAT overall[7], and the TOPCAT study restricted to the Americas[14]. Although there was no significant sex-treatment interaction, spironolactone treatment had a significantly lower multivariate risk of the all-cause mortality in elderly women but not in men, suggesting a possible sex difference in spironolactone treatment concerning allcause mortality.

\section{Limitations}

Firstly, this is a post-hoc, exploratory subgroup analysis that stratified the TOPCAT subjects older than 70 years according to sex and treatment arm, and all findings are hypothesis-generating only. Secondly, the dose and treatments could vary between the Americas and other regions (Russia and Georgia) [21, 22], which might influence researchers to analyze treatment response. Finally, the present study was underpowered to assess differences in outcomes and response to treatment between sex above the age of 75 years. However, there was likely to be better outcomes in this very elderly woman.

\section{Conclusion}


Our analysis showed that elderly women with HFpEF had fewer comorbidities and more likely to have better heart function but had more symptoms and worse quality of life than men. Importantly, elderly women were at a lower risk of the primary composite endpoint than men due to a substantially lower risk of cardiovascular death but not HF hospitalization. It is worth noting that there was a possibility of reducing all-cause mortality associated with spironolactone therapy in elderly women.

\section{PERSPECTIVES AND SIGNIFICANCE}

Although our research showed that spironolactone has no significant effect on improving the prognosis of men and women with HFpEF, the current analysis showed that women with HFpEF have worse clinical symptoms but better outcomes than men with HFpEF. This study suggests that exploring the in-depth mechanism of HFpEF prognostic differences caused by sex differences may help discover new targets for HFpEF treatment in the future.

\section{Abbreviations}

ABBREVIATIONS/ ACRONYMS FULL NAME ACE angiotensin-converting enzyme ARB angiotensin receptor blockers AF. atrial fibrillation BMI body mass index BUN blood urea nitrogen CABG coronary artery bypass grafting CCB calcium channel blockers CV cardiovascular DBP diastolic blood pressure eGFR estimated glomerular filtration rate HFpEF heart failure with a preserved ejection fraction HFrEF heart failure with a reduced ejection fraction HGB hemoglobin HR. heart rate KCCQ Kansas City Cardiomyopathy Questionnaire MI myocardial infarction PCI percutaneous coronary intervention SBP systolic blood pressure

\section{Declarations}

\section{Ethics approval and consent to participate}

No administrative permissions were required to access the raw data, and the data used in this study were anonymized.

\section{Consent for publication}

Written informed consent for publication was obtained from all participants.

\section{Availability of data and material}

The datasets used or analyzed during the current study are available from the National Heart, Lung, and Blood Institute's Biological Specimen and Data Repository Information Coordinating Center (BioLINCC, Calverton, Maryland).

\section{Competing interests}

The authors declare that they have no conflict of interest.

\section{Funding}

This research was partly supported by the Natural Science Foundation of China (NSFC) Projects 81670269 (to S Zhou) and 81801394 (to S Tai).

\section{Authors' contributions}

The work presented here was carried out in collaboration with all authors. SZ defined the study theme and methods. JS and ST collected clinical data, analyzed the data, interpreted the results, and wrote the paper. YG, LT, HY, XL, ZH X, LF are the attending doctor responsible for reviewing and giving suggestions to the manuscript. JS and ST contributed equally to this article. All authors have contributed to, seen, and approved the manuscript.

\section{Acknowledgments}

The authors thank the TOPCAT investigators for conducting the research and making the data available for the public. The TOPCAT trial was funded by the National Heart Lung and Blood Institute (NHLBI), Bethesda, MD (N01 HC45207).

\section{References}

1. Dunlay SM, Roger VL, Redfield MM. Epidemiology of heart failure with preserved ejection fraction. Nature reviews Cardiology. 2017;14(10):591-602. doi:10.1038/nrcardio.2017.65.

2. Lam CSP, Arnott C, Beale AL, Chandramouli C, Hilfiker-Kleiner D, Kaye DM et al. Sex differences in heart failure. European heart journal. 2019;40(47):385968c. doi:10.1093/eurheartj/ehz835.

3. Savarese G, D'Amario D. Sex Differences in Heart Failure. Advances in experimental medicine and biology. 2018;1065:529-44. doi:10.1007/978-3-31977932-4_32.

4. Gomez-Soto FM, Andrey JL, Garcia-Egido AA, Escobar MA, Romero SP, Garcia-Arjona R et al. Incidence and mortality of heart failure: a community-based study. International journal of cardiology. 2011;151(1):40-5. doi:10.1016/j.ijcard.2010.04.055.

5. Brouwers FP, de Boer RA, van der Harst P, Voors AA, Gansevoort RT, Bakker SJ et al. Incidence and epidemiology of new onset heart failure with preserved vs. reduced ejection fraction in a community-based cohort: 11-year follow-up of PREVEND. European heart journal. 2013;34(19):1424-31. doi:10.1093/eurheartj/eht066. 
6. Lam CS, Carson PE, Anand IS, Rector TS, Kuskowski M, Komajda M et al. Sex differences in clinical characteristics and outcomes in elderly patients with heart failure and preserved ejection fraction: the Irbesartan in Heart Failure with Preserved Ejection Fraction (I-PRESERVE) trial. Circulation Heart failure. 2012;5(5):571-8. doi:10.1161/circheartfailure.112.970061.

7. Pitt B, Pfeffer MA, Assmann SF, Boineau R, Anand IS, Claggett B et al. Spironolactone for heart failure with preserved ejection fraction. The New England journal of medicine. 2014;370(15):1383-92. doi:10.1056/NEJMoa1313731.

8. Dewan P, Rorth R, Raparelli V, Campbell RT, Shen L, Jhund PS et al. Sex-Related Differences in Heart Failure With Preserved Ejection Fraction. Circulation Heart failure. 2019;12(12):e006539. doi:10.1161/circheartfailure.119.006539.

9. Desai AS, Lewis EF, Li R, Solomon SD, Assmann SF, Boineau R et al. Rationale and design of the treatment of preserved cardiac function heart failure with an aldosterone antagonist trial: a randomized, controlled study of spironolactone in patients with symptomatic heart failure and preserved ejection fraction. American heart journal. 2011;162(6):966-72.e10. doi:10.1016/j.ahj.2011.09.007.

10. Vidán MT, Blaya-Novakova V, Sánchez E, Ortiz J, Serra-Rexach JA, Bueno H. Prevalence and prognostic impact of frailty and its components in nondependent elderly patients with heart failure. European journal of heart failure. 2016;18(7):869-75. doi:10.1002/ejhf.518.

11. Gironés R. Desire for Information in the Elderly: Interactions with Patients, Family, and Physicians. Journal of cancer education : the official journal of the American Association for Cancer Education. 2015;30(4):766-73. doi:10.1007/s13187-014-0760-5.

12. Tromp J, MacDonald MR, Tay WT, Teng TK, Hung CL, Narasimhan C et al. Heart Failure With Preserved Ejection Fraction in the Young. Circulation. 2018;138(24):2763-73. doi:10.1161/circulationaha.118.034720.

13. Campbell RT, Jhund PS, Castagno D, Hawkins NM, Petrie MC, McMurray JJ. What have we learned about patients with heart failure and preserved ejection fraction from DIG-PEF, CHARM-preserved, and I-PRESERVE? Journal of the American College of Cardiology. 2012;60(23):2349-56. doi:10.1016/j.jacc.2012.04.064.

14. Merrill M, Sweitzer NK, Lindenfeld J, Kao DP. Sex Differences in Outcomes and Responses to Spironolactone in Heart Failure With Preserved Ejection Fraction: A Secondary Analysis of TOPCAT Trial. JACC Heart failure. 2019;7(3):228-38. doi:10.1016/j.jchf.2019.01.003.

15. Faxén UL, Hage C, Donal E, Daubert JC, Linde C, Lund LH. Patient reported outcome in HFpEF: Sex-specific differences in quality of life and association with outcome. Int J Cardiol. 2018;267:128-32. doi:10.1016/j.ijcard.2018.04.102.

16. Israili ZH. Clinical pharmacokinetics of angiotensin II (AT1) receptor blockers in hypertension. Journal of human hypertension. 2000;14 Suppl 1:S73-86. doi:10.1038/sj.jhh.1000991.

17. Soldin OP, Mattison DR. Sex differences in pharmacokinetics and pharmacodynamics. Clinical pharmacokinetics. 2009;48(3):143-57. doi:10.2165/00003088-200948030-00001.

18. Jochmann N, Stangl K, Garbe E, Baumann G, Stangl V. Female-specific aspects in the pharmacotherapy of chronic cardiovascular diseases. European heart journal. 2005;26(16):1585-95. doi:10.1093/eurheartj/ehi397.

19. Eugene AR. Sex based Dosing of Metoprolol in the Elderly using Population Pharmacokinetic Modeling and Simulations. International journal of clinical pharmacology \& toxicology. 2016;5(3):209-15.

20. Ferreira JP, Rossello X, Eschalier R, McMurray JJV, Pocock S, Girerd N et al. MRAs in Elderly HF Patients: Individual Patient-Data Meta-Analysis of RALES, EMPAHSIS-HF, and TOPCAT. JACC Heart failure. 2019;7(12):1012-21. doi:10.1016/j.jchf.2019.08.017.

21. Pfeffer MA, Claggett B, Assmann SF, Boineau R, Anand IS, Clausell N et al. Regional variation in patients and outcomes in the Treatment of Preserved Cardiac Function Heart Failure With an Aldosterone Antagonist (TOPCAT) trial. Circulation. 2015;131(1):34-42. doi:10.1161/circulationaha.114.013255.

22. Bristow MR, Enciso JS, Gersh BJ, Grady C, Rice MM, Singh S et al. Detection and Management of Geographic Disparities in the TOPCAT Trial: Lessons Learned and Derivative Recommendations. JACC Basic to translational science. 2016;1(3):180-9. doi:10.1016/j.jacbts.2016.03.001.

\section{Tables}

Table 1. Characteristics of the patients according to treatment arm. 


\begin{tabular}{|c|c|c|c|c|c|c|c|c|c|}
\hline & \multicolumn{3}{|l|}{ All } & \multicolumn{2}{|c|}{ Placebo arm } & \multicolumn{4}{|c|}{ Spironolactone arm } \\
\hline & Women $(n=898 \rrbracket$ & $\operatorname{Man}(n=721)$ & $P$ & Women $(n=445)$ & $\operatorname{Men}(n=363)$ & $P$ & Women $(n=453)$ & $\operatorname{Men}(n=358)$ & $P$ \\
\hline Age, years & $77.0 \pm 5.3$ & $77.1 \pm 5.1$ & 0.458 & $76.6 \pm 0.2$ & $77 . \pm 0.3$ & 0.116 & $77.4 \pm 0.3$ & $77.2 \pm 0.3$ & 0.621 \\
\hline \multicolumn{10}{|l|}{ Region } \\
\hline Americas, n (\%) & $533(59.4)$ & 498(69.1) & $<0.001$ & $255(56.0)$ & $252(69.4)$ & $<0.001$ & $278(61.4)$ & $246(68.7)$ & 0.030 \\
\hline $\begin{array}{l}\text { Russia/Georgia,n } \\
\text { (\%) }\end{array}$ & $365(40.6)$ & $223(30.9)$ & $<0.001$ & $190(42.7)$ & 111(30.6) & $<0.001$ & 175(38.6) & 112(31.3) & 0.030 \\
\hline LVEF & $63.3 \pm 0.5$ & $58.9 \pm 0.6$ & 0.001 & $61.3 \pm 0.7$ & $59.3 \pm 0.8$ & 0.031 & $61.4 \pm 0.6$ & $58.5 \pm 0.9$ & 0.012 \\
\hline $\begin{array}{l}\text { Atrial fibrillation, } \\
\text { n (\%) }\end{array}$ & $371(41.4)$ & $341(47.4)$ & 0.016 & $188(42.2)$ & 164(45.2) & 0.399 & $183(40.4)$ & $177(49.4)$ & 0.010 \\
\hline \multicolumn{10}{|l|}{$\begin{array}{l}\text { Coronary artery } \\
\text { disease }\end{array}$} \\
\hline Angina, n (\%) & $363(40.4)$ & $316 \llbracket 43.9 \rrbracket$ & 0.166 & 193(43.4) & $164(45.2)$ & 0.602 & $170(37.5)$ & $152(42.5)$ & 0.154 \\
\hline $\mathrm{Ml}, \mathrm{n}(\%)$ & 168(18.7) & $223 \llbracket 30.9 \rrbracket$ & $<0.001$ & $86(19.3)$ & $120(33.1)$ & $<0.001$ & $82(18.1)$ & $103(28.8)$ & $<0.00$ \\
\hline CABG, n (\%) & $68(7.6)$ & $161 \rrbracket 22.3 \rrbracket$ & $<0.001$ & $41(9.2)$ & $89(24.5)$ & $<0.001$ & $27(6.0)$ & $72(20.1)$ & $<0.00$ \\
\hline PCl, n (\%) & $112(12.5)$ & 136囚18.9囚 & $<0.001$ & $49(11.0)$ & $76(20.9)$ & $<0.001$ & $63(13.9)$ & $60(16.8)$ & 0.261 \\
\hline $\begin{array}{l}\text { Hypertension, } n \\
\text { (\%) }\end{array}$ & $835(93.0)$ & $643 \llbracket 89.2 \rrbracket$ & 0.007 & 417(93.7) & $326(89.8)$ & 0.042 & $418(92.3)$ & $317(88.5)$ & 0.071 \\
\hline $\begin{array}{l}\text { Diabetes } \\
\text { mellitus, } n \text { (\%) }\end{array}$ & $252 \rrbracket 28.1 \rrbracket$ & $229 \llbracket 31.2 \rrbracket$ & 0.105 & $117(26.3)$ & 123(33.9) & 0.019 & $135(29.8)$ & $106(29.6)$ & 0.953 \\
\hline $\begin{array}{l}\text { Dyslipidemia, n } \\
\text { (\%) }\end{array}$ & $515857.3 \rrbracket$ & $477 \llbracket 66.2 \rrbracket$ & $<0.001$ & $258(58.0)$ & $250(68.9)$ & 0.001 & $257(56.7)$ & $227(63.4)$ & 0.054 \\
\hline $\begin{array}{l}\text { Tobacco use, } n \\
\text { (\%) }\end{array}$ & $224 \rrbracket 24.8 \rrbracket$ & $482 \bowtie 66.9 \rrbracket$ & $<0.001$ & $114(25.6)$ & $236(65.0)$ & $<0.001$ & $110(24.3)$ & $246(67.8)$ & $<0.00$ \\
\hline COPD, n (\%) & 83囚9.24囚 & $118 \llbracket 47.4 \rrbracket$ & $<0.001$ & $39(8.6)$ & $63(17.6)$ & $<0.001$ & $44(9.7)$ & $55(15.4)$ & 0.015 \\
\hline $\begin{array}{l}\text { Heart rate, } \\
\text { beats/min }\end{array}$ & $69.0 \pm 10.4$ & $67.2 \pm 10.2$ & 0.002 & $69.0 \pm 0.5$ & $67.5 \pm 0.5$ & 0.049 & $69.1 \pm 0.5$ & $66.8 \pm 0.6$ & 0.013 \\
\hline $\mathrm{SBP}, \mathrm{mm} \mathrm{Hg}$ & $130.5 \pm 14.3$ & $126.8 \pm 13.5$ & $<0.001$ & $131.1 \pm 0.7$ & $126.6 \pm 0.7$ & $<0.001$ & $129.9 \pm 0.7$ & $127.1 \pm 0.7$ & 0.009 \\
\hline DBP, mm Hg & $74.5 \pm 11.1$ & $71.9 \pm 10.7$ & $<0.001$ & $74.5 \pm 0.6$ & $71.6 \pm 0.6$ & $<0.001$ & $72.5 \pm 0.5$ & $72.1 \pm 0.6$ & 0.006 \\
\hline $\begin{array}{l}\text { Body mass } \\
\text { index, } \mathrm{kg} / \mathrm{m}^{2}\end{array}$ & $30.9 \pm 6.2$ & $30.1 \pm 5.8$ & 0.011 & $31.0 \pm 0.3$ & $30.0 \pm 0.3$ & 0.024 & $30.7 \pm 0.3$ & $30.1 \pm 0.3$ & 0.164 \\
\hline $\begin{array}{l}\text { Serum } \\
\text { potassium, } \\
\mathrm{mmol} / \mathrm{l}\end{array}$ & $4.2 \pm 0.4$ & $4.3 \pm 0.5$ & 0.010 & $4.3 \pm 0.0$ & $4.29 \pm 0.0$ & 0.108 & $4.2 \pm 0.2$ & $4.3 \pm 0.0$ & 0.349 \\
\hline $\begin{array}{l}\text { Blood urea } \\
\text { nitrogen, } \mathrm{mg} / \mathrm{dl}\end{array}$ & $16.2 \pm 14.2$ & $20.1 \pm 14.3$ & $<0.001$ & $16.9 \pm 0.7$ & $18.8 \pm 0.7$ & 0.005 & $15.4 \pm 0.6$ & $21.4 \pm 0.8$ & $<0.00$ \\
\hline Creatinine, mg/dl & $1.0 \pm 0.3$ & $1.3 \pm 0.3$ & $<0.001$ & $1.0 \pm 0.0$ & $1.2 \pm 0.0$ & $<0.001$ & $1.0 \pm 0.0$ & $1.3 \pm 0.0$ & $<0.00$ \\
\hline $\begin{array}{l}\text { Estimated GFR, } \\
\mathrm{ml} / \mathrm{min} / 1.73 \mathrm{~m}^{2}\end{array}$ & $60.8 \pm 17.6$ & $64.2 \pm 17.5$ & $<0.001$ & $60.0 \pm 0.8$ & $65.1 \pm 1.0$ & $<0.001$ & $61.5 \pm 0.8$ & $63.3 \pm 0.9$ & 0.073 \\
\hline Hemoglobin, g/dl & $12.6 \pm 1.8$ & $13.3 \pm 2.4$ & $<0.001$ & $12.8 \pm 0.1$ & $13.2 \pm 0.1$ & $<0.001$ & $12.5 \pm 0.1$ & $13.4 \pm 0.1$ & $<0.00$ \\
\hline $\begin{array}{l}\text { NYHA functional } \\
\text { classes III-IV, } n \\
(\%)\end{array}$ & $346(38.5)$ & $227(31.5)$ & 0.003 & 172 & 104 & 0.003 & 174 & 123 & 0.234 \\
\hline $\begin{array}{l}\text { KCCQ overall } \\
\text { score }\end{array}$ & $54.1 \pm 19.9$ & $61.9 \pm 21.3$ & $<0.001$ & $53.8 \pm 0.9$ & $61.8 \pm 1.1$ & $<0.001$ & $54.3 \pm 1.0$ & $62.0 \pm 1.2$ & $<0.00$ \\
\hline PHQ-9 score & $5.3 \pm 9.2$ & $4.8 \pm 8.8$ & 0.065 & $5.5 \pm 0.6$ & $4.1 \pm 0.8$ & 0.078 & $5.0 \pm 0.7$ & $5.4 \pm 0.3$ & 0.377 \\
\hline $\begin{array}{l}\text { Any anti- } \\
\text { hypertensive } \\
\text { drugs, } \mathrm{n}(\%)\end{array}$ & 892(99.4) & $713(99.0)$ & 0.334 & $441(99.1)$ & $360(99.2)$ & 0.825 & 451(99.6) & $353(98.6)$ & 0.144 \\
\hline $\begin{array}{l}\text { ACEl or ARB, } n \\
(\%)\end{array}$ & $730(81.4)$ & $568(78.9)$ & 0.210 & $365(82.0)$ & $282(77.7)$ & 0.126 & $365(80.6)$ & $286(80.0)$ & 0.807 \\
\hline $\begin{array}{l}\text { Beta-blocker, n } \\
(\%)\end{array}$ & $670(74.7)$ & $558(77.5)$ & 0.189 & $333(74.8)$ & 286(78.8) & 0.180 & $337(74.4)$ & $272(76.0)$ & 0.604 \\
\hline CCB, n (\%) & $356(39.7)$ & $256(35.6)$ & 0.089 & 186(41.8) & 125(34.4) & 0.033 & $170(37.5)$ & $131(36.6)$ & 0.784 \\
\hline
\end{tabular}




\begin{tabular}{|c|c|c|c|c|c|c|c|c|c|}
\hline Diuretic, n (\%) & $754(84.1)$ & 604(83.9) & 0.927 & $378(84.9)$ & $309(85.1)$ & 0.929 & $376(83.0)$ & 295(82.4) & 0.822 \\
\hline $\begin{array}{l}\text { Other anti- } \\
\text { hypertensive } \\
\text { drugs, } \mathrm{n}(\%)\end{array}$ & $110(12.3)$ & 115(16.0) & 0.032 & $56(12.6)$ & $55(15.2)$ & 0.290 & $54(11.9)$ & $60(16.8)$ & 0.049 \\
\hline Aspirin, $n(\%)$ & $552(61.5)$ & $460(63.9)$ & 0.332 & $278(62.5)$ & $233(64.2)$ & 0.608 & $274(60.5)$ & $227(63.4)$ & 0.395 \\
\hline Nitrate, n (\%) & $143(15.9)$ & 113(15.7) & 0.892 & 73(16.4) & $57(15.7)$ & 0.789 & $70(15.5)$ & $56(15.6)$ & 0.941 \\
\hline $\begin{array}{l}\text { Any } \\
\text { hypoglycemic, n } \\
\text { (\%) }\end{array}$ & $202(22.5)$ & 195(27.1) & 0.034 & $93(20.9)$ & 103(28.4) & 0.013 & $109(24.1)$ & $92(25.7)$ & 0.592 \\
\hline Statin, n (\%) & $420(46.8)$ & $445(61.8)$ & $<0.001$ & $204(45.8)$ & $220(60.6)$ & $<0.001$ & 216(47.7) & $225(62.8)$ & $<0.00$ \\
\hline Warfarin, n (\%) & $231(25.8)$ & $229(31.8)$ & 0.007 & $116(26.1)$ & 115(31.7) & 0.078 & $115(25.4)$ & 114(31.8) & 0.043 \\
\hline $\begin{array}{l}\text { Other CV } \\
\text { medication, } n \text { (\%) }\end{array}$ & $396(44.1)$ & $410(56.9)$ & $<0.001$ & 192(43.1) & $207(57.0)$ & $<0.001$ & $204(45.0)$ & $203(56.7)$ & 0.001 \\
\hline $\begin{array}{l}\text { Selective } \\
\text { serotonin } \\
\text { reuptake } \\
\text { inhibitor, n (\%) }\end{array}$ & $78(8.7)$ & $50(6.9)$ & 0.195 & $39(87.6)$ & $26(7.2)$ & 0.406 & $39(8.6)$ & $24(6.7)$ & 0.314 \\
\hline
\end{tabular}

Table 1. Values are mean \pm SD or $\mathrm{n}(\%)$. CABG = coronary artery bypass graft; $\mathrm{PCl}$ = percutaneous coronary intervention; COPD = chronic obstructive pulmonary disease; GFR = glomerular filtration rate; HF = heart failure; $\mathrm{LVEF}=$ left ventricular ejection fraction; $\mathrm{MI}$ = myocardial infarction; $\mathrm{SBP}=$ systolic blood pressure; $\mathrm{DBP}=$ diastolic blood pressure; $\mathrm{KCCQ}=$ Kansas City Cardiomyopathy Questionnaire; NYHA = New York Heart Association; PHQ-9 = Patient Health Questionnaire 9th edition; $\mathrm{ACE}$ = angiotensin-converting enzyme; $\mathrm{ARB}=$ angiotensin receptor blocker; $\mathrm{CCB}=$ calcium channel blocker; $\mathrm{CV}=$ cardiovascular.

Table 2. Differences in outcomes between women and men

\begin{tabular}{|c|c|c|c|c|c|c|c|c|c|}
\hline & \multicolumn{3}{|l|}{ All } & \multicolumn{2}{|c|}{ Placebo arm } & \multicolumn{4}{|c|}{ Spironolactone arm } \\
\hline & Women $(n=898 \rrbracket$ & $\operatorname{Man}(n=721)$ & $P$ & Women(n=445) & $\operatorname{Men}(n=363)$ & $P$ & Women(n=453) & Men(n=358) & $P$ \\
\hline $\begin{array}{l}\text { Primary } \\
\text { outcome, n (\%) }\end{array}$ & $165(18.4)$ & 198(27.5) & $<0.001$ & $84 \llbracket 18.9 \rrbracket$ & 102区28.1区 & 0.002 & 81ه17.9凶 & $96 \rrbracket 26.8 \rrbracket$ & 0.002 \\
\hline $\begin{array}{l}\text { CV mortality, n } \\
(\%)\end{array}$ & $80(8.9)$ & $107(14.8)$ & $<0.001$ & 47ه10.6ه & $56 \rrbracket 15.4 \rrbracket$ & 0.039 & $33 \llbracket 7.3 \rrbracket$ & $51 \otimes 14.2 \rrbracket$ & 0.001 \\
\hline $\begin{array}{l}\text { HF } \\
\text { hospitalization, } \\
\text { n (\%) }\end{array}$ & $120(13.4)$ & 131(18.2) & 0.008 & $60 \otimes 13.5 \rrbracket$ & 69ه19.0ه & 0.033 & $60 \rrbracket 13.2 \rrbracket$ & $62 \rrbracket 17.3 \rrbracket$ & 0.107 \\
\hline $\begin{array}{l}\text { All-cause } \\
\text { mortality, n (\%) }\end{array}$ & $140(15.6)$ & 183(25.4) & $<0.001$ & $140(31.5)$ & $183(50.4)$ & $<0.001$ & $59 ه 13.0 \otimes$ & $92 \rrbracket 25.7 \rrbracket$ & $<0.001$ \\
\hline $\begin{array}{l}\text { All-cause } \\
\text { hospitalization, } \\
\text { n (\%) }\end{array}$ & $422(47.0)$ & $384(52.3)$ & 0.012 & $216 \rrbracket 48.5 \rrbracket$ & $193 \llbracket 53.2 \rrbracket$ & 0.191 & $206 \rrbracket 45.5 \rrbracket$ & 191ه53.4囚 & 0.026 \\
\hline
\end{tabular}

Table 2. Values are n (\%). Chi-square tests for women vs. men. Abbreviations as in Tables 1.

Table 3. Univariate and Multivariate hazard ratios and interaction terms between sex and treatment response for all outcomes 


\begin{tabular}{|c|c|c|c|c|c|c|c|}
\hline Outcome & $\begin{array}{l}\text { Placebo } \\
(n=808)\end{array}$ & $\begin{array}{l}\text { Spironolactone } \\
(\mathrm{n}=811)\end{array}$ & $\begin{array}{l}\text { Univariate } \\
\mathrm{HR}(95 \% \mathrm{Cl})\end{array}$ & $P$ & $\begin{array}{l}\text { Multivariate } \\
\text { HR (95\% Cl) }\end{array}$ & $P$ & $P$ interaction \\
\hline Primary outcome & & & & & & & 0.016 \\
\hline Women, n (\%) & $84(10.4)$ & $81(10.0)$ & $0.95(0.70-1.29)$ & 0.730 & $0.91(0.67-1.25)$ & 0.580 & \\
\hline Men, n (\%) & $102(12.6)$ & $96(11.8)$ & $0.90(0.68-1.19)$ & 0.475 & $0.88(0.66-1.17)$ & 0.377 & \\
\hline CV mortality & & & & & & & 0.214 \\
\hline Women, n (\%) & $47(5.8)$ & $33(4.1)$ & $0.70(0.45-1.09)$ & 0.117 & $0.66(0.42-1.03)$ & 0.068 & \\
\hline Men, n (\%) & $102(12.6)$ & $96(11.8)$ & $0.87(0.60-1.28)$ & 0.483 & $0.81(0.55-1.20)$ & 0.287 & \\
\hline HF hospitalization & & & & & & & 0.211 \\
\hline Women, n (\%) & $60(7.4)$ & $60(7.4)$ & $0.98(0.67-1.40)$ & 0.921 & $0.93(0.68-1.33)$ & 0.683 & \\
\hline Men, n (\%) & $69(8.5)$ & $62(7.6)$ & $0.87(0.62-1.23)$ & 0.436 & $0.87(0.61-1.24)$ & 0.449 & \\
\hline All-cause mortality & & & & & & & 0.119 \\
\hline Women, n (\%) & $81(10.0)$ & $59(7.3)$ & $0.73(0.52-1.01)$ & 0.062 & $0.68(0.48-0.96)$ & 0.028 & \\
\hline Men, n (\%) & 91(11.3) & $92(11.3)$ & $0.97(0.73-1.30)$ & 0.857 & $0.95(0.70-1.28)$ & 0.720 & \\
\hline All-cause hospitalization & & & & & & & 0.594 \\
\hline Women, $\mathrm{n}(\%)$ & $216(26.7)$ & $206(25.4)$ & $0.89(0.73-1.07)$ & 0.212 & $0.84(0.69-1.02)$ & 0.086 & \\
\hline Men, n (\%) & 193(23.9) & 191(23.6) & $0.97(0.80-1.19)$ & 0.783 & $0.97(0.79-1.19)$ & 0.779 & \\
\hline
\end{tabular}

Table 3. Values are $\mathrm{n}(\%)$. Cox proportional hazards model to explore the associations between sex and the outcomes. Abbreviations as in Tables 1.

\section{Figures}



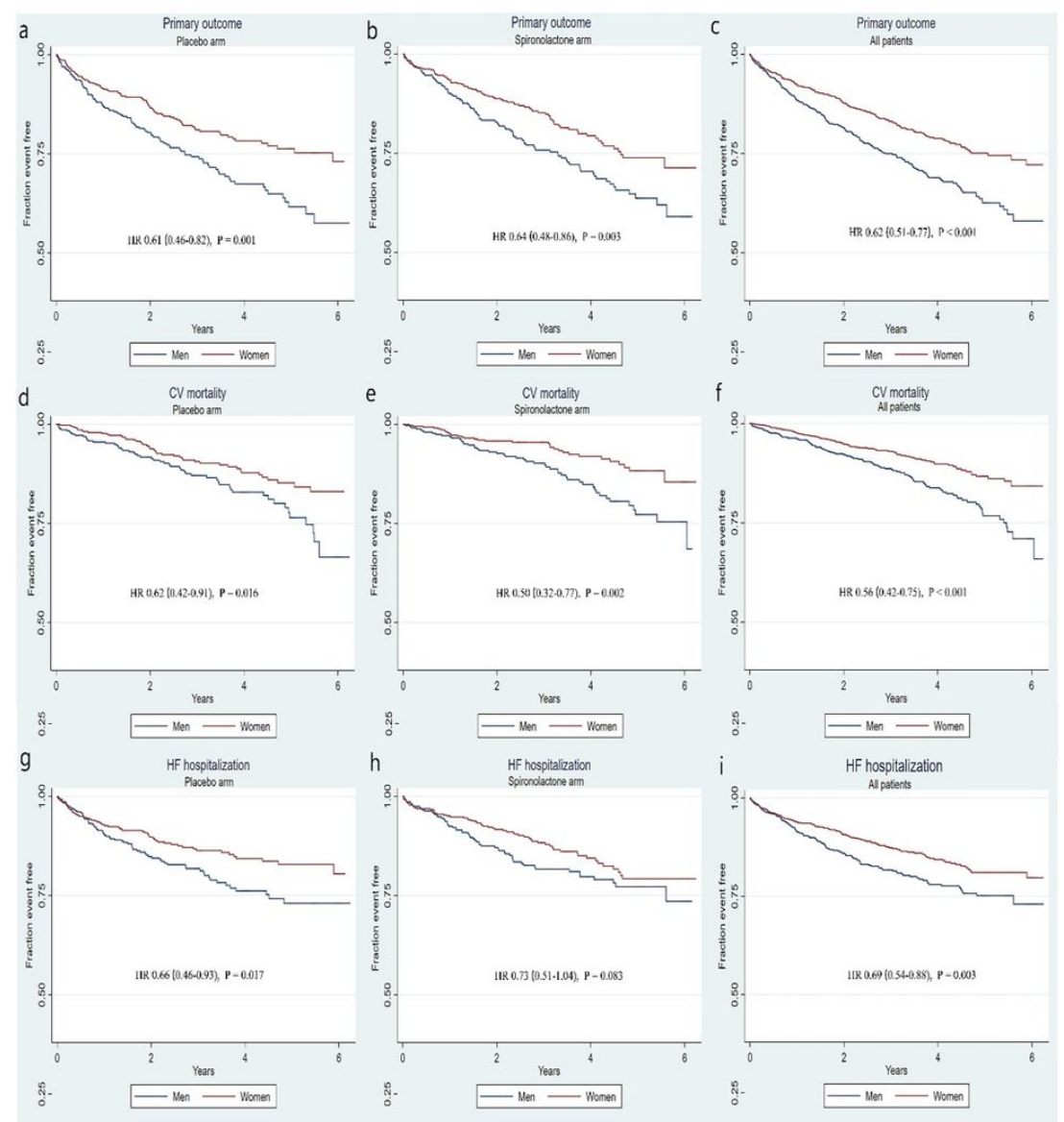

\section{Figure 1}

Kaplan-Meier survival curves for primary outcomes and components stratified by sex according to treatment. There was a significant association between sex and the primary outcome, CV mortality in either placebo arm or spironolactone arm. Women had a significantly lower rate of all the primary outcome in all patients; $\mathrm{CV}=$ cardiovascular diseases, $\mathrm{HF}=$ heart failure; $\mathrm{HR}=$ hazard ratio 


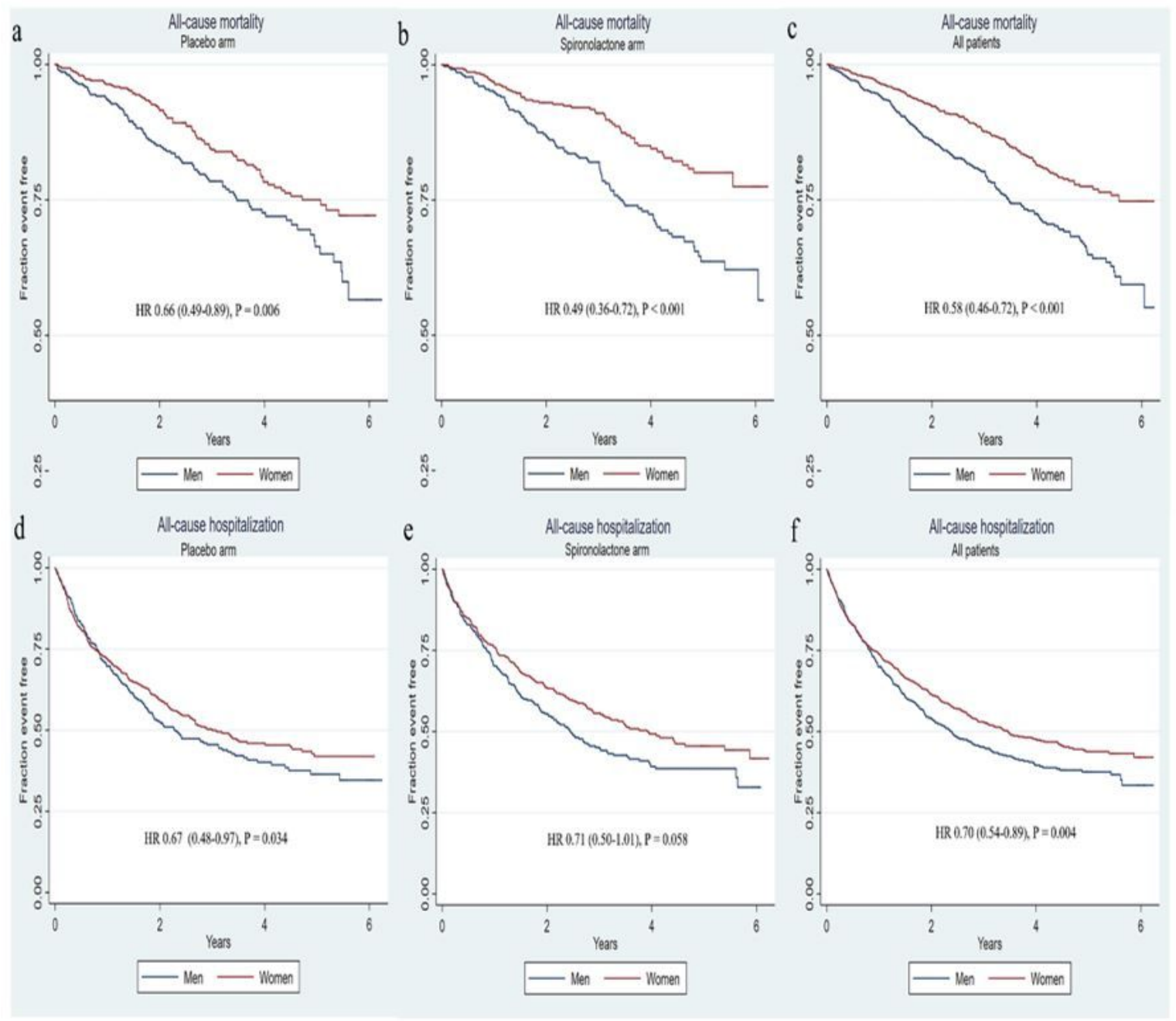

Figure 2

Kaplan-Meier survival curves for secondary outcomes and components stratified by sex according to treatment. Women were associated with a significantly reduced likelihood of all-cause mortality in the placebo arm, spironolactone arm, and all patients. No significant result was observed for all-cause hospitalization 


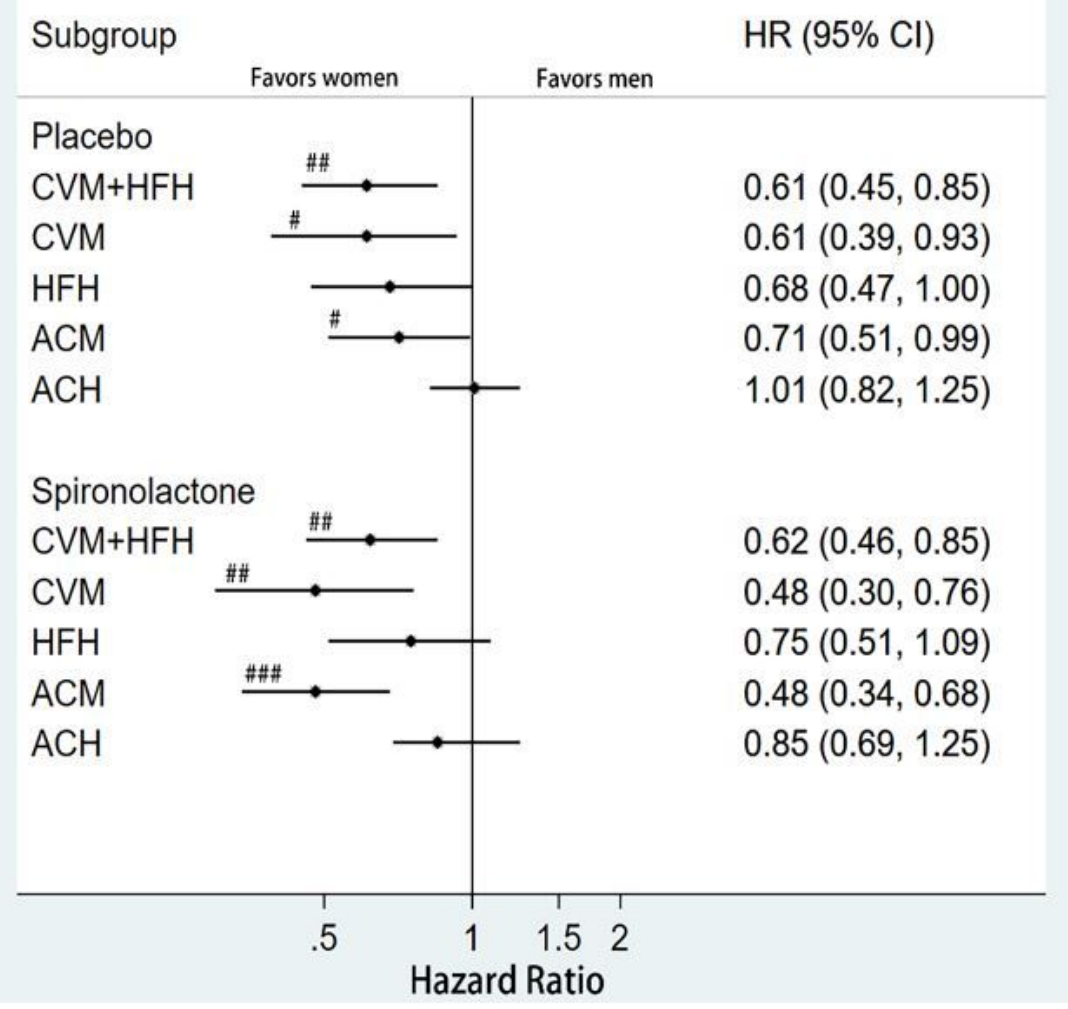

Figure 3

Multivariate hazard ratios for primary and secondary outcomes according to treatment arm and stratified by sex. \# $P<0.05$, \#\# $P<0.01$, \#\#\# $P<0.001$. $\mathrm{ACM}=$ all-cause mortality; $\mathrm{CVH}=$ cardiovascular hospitalization; $\mathrm{CVM}=$ cardiovascular mortality; $\mathrm{HFH}=$ heart failure hospitalization; $\mathrm{ACH}=$ all-cause hospitalization

\section{Supplementary Files}

This is a list of supplementary files associated with this preprint. Click to download.

- Supplementalfile.docx 